\title{
desenvolvimento

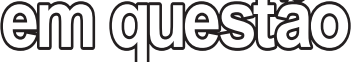

\section{Papel dos Supermercados na Etapa da Geração e Descarte do Lixo e o Reflexo na Questão Ambiental}

\author{
Simone Beatriz Ceretta ${ }^{1}$ \\ Lurdes Marlene Seide Froemming ${ }^{2}$
}

\begin{abstract}
Resumo
0 presente estudo tem como objetivo discutir o papel dos supermercados no descarte de produtos, essencialmente no que se refere à produção de lixo doméstico oriundo das compras supermercadistas. Inicia-se com uma abordagem reflexiva baseada em pesquisa bibliográfica e agregam-se resultados de pesquisa exploratória. Foram investigados três supermercados localizados no perímetro central do município de ljuí/RS, incluindo seus gestores e consumidores. Para a coleta de dados, foi utilizado 0 método survey de pesquisa, com aplicação de 150 questionários a consumidores e entrevistas com os gestores dos três estabelecimentos em análise. Realizou-se ainda pesquisa participante com 0 acompanhamento da produção de lixo oriundo de compras em supermercados. Os resultados demonstram que as famílias produzem uma quantidade significativa de lixo, advinda de compras nas lojas, a qual é descartada no lixo comum, acarretando problemas ambientais e de saúde para a população. Neste processo, constatou-se que os gestores das três empresas executam algumas ações para reduzir os impactos de suas operações, entretanto acabam minimizando a sua responsabilidade quanto à preservação ambiental, transferindo-a ao fabricante e ao consumidor.
\end{abstract}

Palavras-chave: Descarte. Lixo. Supermercados.

Graduada em Administração, Especialista em Marketing e Mestre em Desenvolvimento. Professora do Instituto Federal Farroupilha, campus de Santo Augusto/RS. simone@sa.iffarroupilha.edu.br

2 Graduada em Administração, especialista em Economia Rural, mestre em Administração e doutora em Administração. Professora Titular da Universidade Regional do Noroeste do Estado do Rio Grande do Sul - Unijuí. lurdesf@unijui.edu.br 


\title{
THE SUPERMARKETS' ROLE IN THE GENERATION AND DISCARD OF GARBAGE AND THE EFFECT IN THE ENVIRONMENTAL ISSUE
}

\begin{abstract}
This study aims to discuss the role of supermarkets in the disposal of products, primarily in relation to the production of household waste arising from supermarket shopping. It begins with a reflective approach based on literature and adds up the results of exploratory research. We investigated three supermarkets located on the perimeter of a central city of ljuí/RS, including their managers and consumers. To collect data, we used the method of survey research with application of 150 questionnaires to consumers and interviews with managers of three supermarkets in analysis. We carried out further research participant with monitoring the production of garbage coming from shopping in supermarkets. The results show that households produce a significant amount of waste, arising from purchases in stores, which is discarded in the trash, resulting in environmental and health problems for the population. In this process, it was found that the managers of the three companies perform some actions to reduce the impacts of their operations, however, ultimately minimizing their liability regarding environmental preservation, transferring it to the manufacturer and the consumer.
\end{abstract}

Keywords: Discard. Garbage. Supermarkets. 
Muitas transformações decorrentes do processo de globalização nos anos 90, como o deslocamento dos mercados, aumento da concorrência, o surgimento de novas tecnologias e, principalmente, as necessidades emergentes dos consumidores, exigiram mudanças significativas no setor varejista. Os supermercados, considerados um dos mais importantes representantes desse segmento, tiveram de se ajustar, adotando novas tecnologias em seus processos, formulando novas estratégias mercadológicas para enfrentar a concorrência e desenvolvendo uma nova visão do negócio, com foco no consumidor. Além disso, o desafio varejista é maior por sua importância no processo de desenvolvimento sustentável, especialmente no que se refere aos impactos ambientais resultantes de suas operações, que produzem quantidades significativas de lixo doméstico.

Os supermercados assumem atualmente uma posição muito importante no canal de distribuição e possuem responsabilidades, essencialmente em relação ao descarte de produtos e à produção de lixo doméstico, exigindo-se de seus gestores novas formas de agir e de pensar a organização. Em relação à dimensão ambiental, encontra-se neste quesito o maior gargalo da atuação dos supermercados. Evidentemente que o impacto do varejo é pequeno quando comparado ao provocado pelas indústrias, porém a quantidade de lixo resultante das compras supermercadistas e a quantidade de embalagens e sacolas resultantes dessas compras fazem do varejo um grande produtor e repassador de produtos geradores de lixo doméstico. Daí, a relevância de considerar o seu papel como elo entre a indústria e o consumidor dos produtos distribuídos via supermercados.

A preocupação maior é com o descarte dos produtos e o destino dos resíduos que se torna um problema, em especial nas grandes cidades. Sendo assim, os supermercados possuem uma participação importante na busca de alternativas relacionadas principalmente ao descarte de produtos. O descarte das compras supermercadistas acaba contribuindo para a produção de grande quantidade de lixo doméstico, origem de poluição ambiental significativa, sendo necessário o desenvolvimento de ações que possam minimizar essa 
produção e seus impactos. Alternativas como o uso de sacolas retornáveis e biodegradáveis, a criação de locais para coleta de pilhas e lâmpadas usadas, as compras de fornecedores considerados socialmente responsáveis, são algumas ações que necessitam ser reforçadas a fim de reduzir o impacto provocado no meio ambiente, porém essas são apenas algumas das ações que devem ser vislumbradas para um efetivo combate dos focos de destruição ambiental.

O presente estudo busca discutir o papel dos supermercados no descarte de produtos, essencialmente no que se refere à produção de lixo doméstico oriundo das compras supermercadistas. Inicia-se com uma abordagem reflexiva baseada em pesquisa bibliográfica e agregam-se resultados de pesquisa exploratória com dados primários, ainda que, em dimensão exploratória, sem intenção de apontar dados conclusivos. Para tanto, foram investigados três supermercados localizados no perímetro central do município de Ijuí/RS, incluindo seus consumidores. O artigo está estruturado em três partes. Em um primeiro momento apresenta-se o referencial teórico acerca do tema em estudo. Na segunda parte são descritos os procedimentos metodológicos utilizados e, na terceira, apresentam-se os resultados obtidos na pesquisa, bem como as conclusões extraídas da investigação.

\section{Referencial Teórico}

\section{A Etapa de Descarte no Processo Decisório de Compra do Consumidor}

O último estágio do processo decisório do consumidor é o despojamento ou descarte. Trata-se do "descarte do produto não consumido ou do que dele restou" (Engel; Blackwell; Miniard, 2000, p. 92). Para os autores, esse problema sempre existiu, porém só recentemente surgiu como foco de pesquisas e estratégias de marketing, devido aos graves problemas am- 
bientais que emergem com mais força a cada dia. Neste estágio, os consumidores têm diversas opções incluindo o descarte direto, a reciclagem ou o remarketing (revenda de produtos).

O consumidor pode desfazer-se dos produtos definitiva ou temporariamente. "Os consumidores se desfazem das coisas, seja porque já realizaram sua função ou possivelmente porque não são mais adequadas à visão que eles têm de si próprios" (Solomon, 2002, p. 248). O autor complementa ainda que, como as pessoas com frequência formam fortes laços com os produtos, a decisão de se desfazer deles pode ser dolorosa. A Figura 1 ilustra as opções de que o consumidor dispõe para efetuar o descarte das mercadorias.

\section{Figura 1 - Opções do Consumidor para Realizar o Descarte}

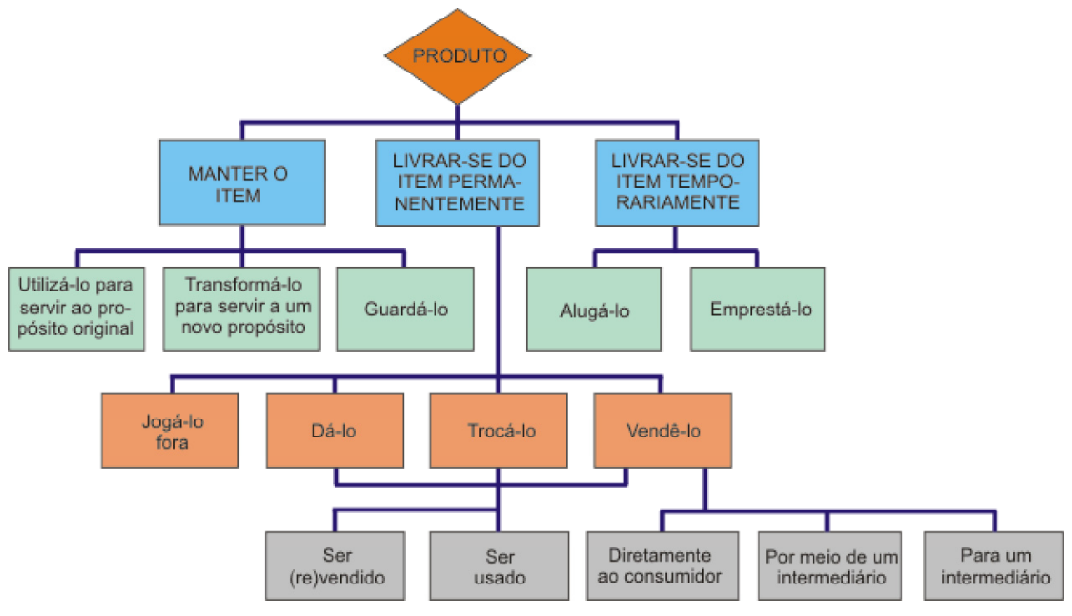

Fonte: Solomon (2002, p. 249).

Quando o consumidor julga que um produto não possui mais utilidade, ele tem várias opções relacionadas por Solomon (2002): (1) manter o item; (2) descartá-lo de modo temporário; (3) desfazer-se dele permanentemente. Em muitos casos, um novo produto é comprado, mesmo que o antigo funcione. Isso ocorre por um desejo de se ter novas características, uma alteração no ambiente da pessoa ou uma mudança no papel ou na autoimagem do indivíduo. 
Os indivíduos estão agindo de acordo com seus valores por meio do poder de suas decisões de compra [...]. Numa tentativa individual de se protegerem e de protegerem o planeta, esses consumidores estão moldando uma nova tendência denominada consumerismo ambiental, comprando produtos que consideram verdes e deixando produtos não verdes na prateleira (Ottman, 1994, p. 8).

Quando exercem o poder de suas decisões de compra os consumidores estão agindo de acordo com seus valores e princípios, o que tem levado as empresas a repensarem seus processos e suas filosofias, sob pena de perderem mercado e capital (Ottman, 1994). A crescente preocupação com o meio ambiente, incrementada pelo aumento da difusão do consumo consciente tem proporcionado um destaque especial à etapa de descarte no processo decisório de compra.

Na cultura vigente, do supérfluo, quase tudo é descartável, criando-se então, uma imensidão de lixo e produtos não reaproveitáveis, que levam anos para se decompor. Um dos grandes fatores que contribuem para o agravamento deste quadro é o sistema produtivo de compras em supermercados, haja vista que a forma atual gera muitos resíduos, tais como inúmeras sacolas plásticas e caixas de papelão, além do consumo de combustível (e geração de poluentes) referente ao deslocamento do consumidor até os supermercados para fazer suas compras.

Ainda que a etapa do descarte refira-se a todos os produtos, muito frequentemente ela está associada unicamente às embalagens, por serem identificadas como um dos mais sérios problemas das modernas sociedades industrializadas, especialmente aqueles relacionados ao lixo urbano (Palhares, 2003). Nos últimos anos, a preocupação com a preservação ambiental e suas relações com o descarte de resíduos sólidos tem garantido mais espaço nos fóruns governamentais e nos debates da população em geral, principalmente nos países mais desenvolvidos. Prova disso é que a União Europeia promulgou uma Diretiva que trata especificamente do assunto 
"embalagem e descarte de embalagem", estabelecendo rigorosos níveis de recuperação e reciclagem de resíduos sólidos em cada país-membro (Palhares, 2003, p. 15).

Dados de um levantamento realizado em 2002 pela Research International indicam que o consumidor brasileiro está começando a despertar para a importância da preservação ambiental. O estudo mostrou que $94,7 \%$ dos brasileiros já tinham ouvido falar em reciclagem ou materiais recicláveis e $27 \%$ deles já separam materiais para esse fim, $34 \%$ mostraram-se favoráveis à possibilidade de adotar o hábito e $13 \%$ declararam estar muito predispostos a seguir esta rotina (Palhares, 2003).

A reciclagem passou a ser considerada um método de descarte, e os produtos que passaram a incorporar componentes reciclados em suas embalagens, ou até mesmo em sua composição, vêm ganhando a preferência dos consumidores. As empresas devem priorizar as questões ambientais nas suas decisões de marketing, pois os consumidores tornaram-se mais conscientes da fragilidade do meio natural, abrindo espaço para produtos ecologicamente melhores. Da mesma forma, empresas ou produtos que não atentarem para esta realidade, deixando de respeitar um nível mínimo de responsabilidade ambiental, poderão ser fortemente boicotados pelos consumidores que, a cada dia mais, começam a apresentar um comportamento "verde" nas suas decisões de compra.

\section{O lixo como Resultado da Atividade Supermercadista}

O varejo é conceituado por Kotler e Armstrong (1999) como sendo todas as atividades envolvidas na venda de bens ou serviços diretamente aos consumidores finais para seu uso pessoal. Desta forma, empresas que atuam no segmento varejista precisam preocupar-se com o descarte de embalagens, o volume e tipo de lixo gerado e a armazenagem de produtos 
pós-consumo (Aligleri; Aligleri; Kruglianskas, 2009), uma vez que atuam em uma posição central, reconhecidas como o elo de ações corporativas e individuais (Figura 2).

Figura 2 - Oportunidades para o Varejo:

Conexões da Cadeia de Valor do Varejo

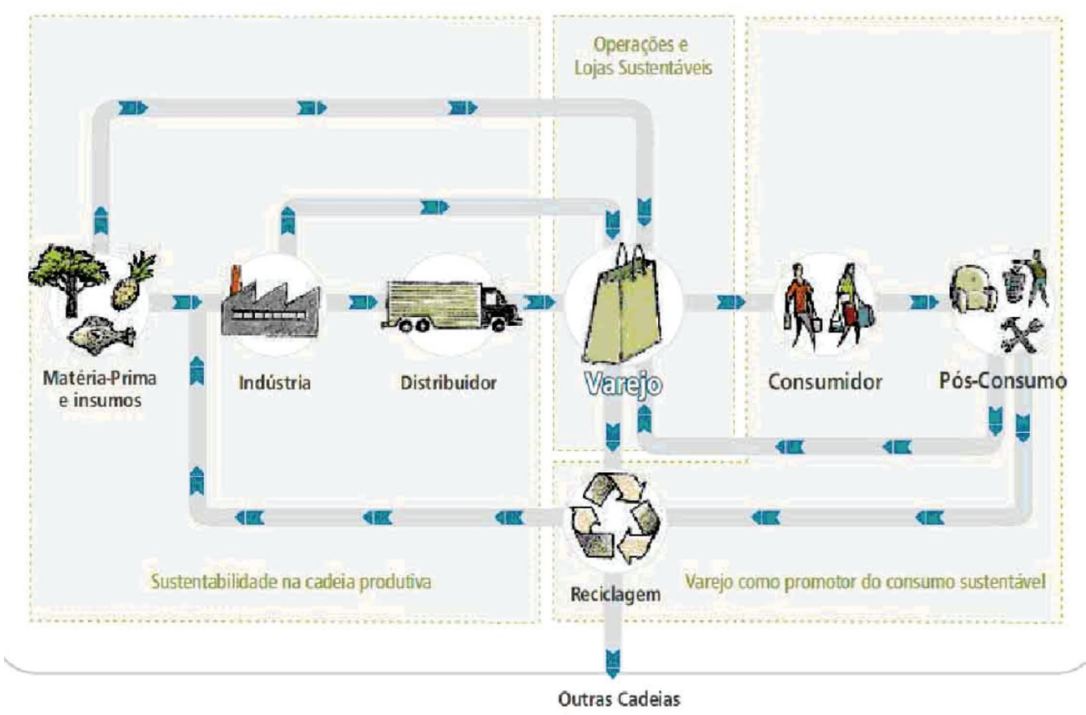

Fonte: Parente et al (2009, p. 17).

No canal de distribuição, o varejo supermercadista possui poder de barganha sobre a indústria, podendo exigir de seus fornecedores produtos mais sustentáveis, exercendo poder ainda, sobre o consumidor, que irá adquirir os produtos por eles ofertados em suas lojas. O resultado destas operações poderá resultar em maior ou menor quantidade de lixo, o qual é considerado um dos grandes agravantes dos problemas ambientais.

O varejo supermercadista trabalha com inúmeras linhas de produtos que, na maioria, ao serem consumidas acabam por ser destinadas ao lixo comum, como elucidado na Figura 2. Ao longo dos anos o lixo passou a ser uma questão de interesse global, pois os problemas provocados pelo 
seu acúmulo são os mesmos em qualquer lugar do mundo. Produzidos em todos os estágios das atividades humanas, os resíduos, em termos tanto de composição quanto de volume, provocam danos à saúde humana e impactos sobre o meio ambiente (solo, água, ar e paisagens).

Fadini e Fadini (2001) observam que o lixo é uma grande diversidade de resíduos sólidos de diferentes procedências, dentre eles o resíduo sólido urbano gerado nas residências. O lixo faz parte da história do homem e a sua produção é inevitável. Na Idade Média acumulava-se pelas ruas e imediações das cidades, provocando sérias epidemias e causando a morte de milhões de pessoas. A partir da Revolução Industrial iniciou-se o processo de urbanização, provocando a migração do homem do campo para as cidades, o que resultou num grande crescimento populacional, favorecido também pelo avanço da Medicina e consequente aumento da expectativa de vida.

Em decorrência, os impactos ambientais galgaram para um grau de magnitude alto, devido aos mais diversos tipos de poluição, dentre eles a poluição gerada especificamente pelo lixo. Assim, o lixo passou a ser tratado como um problema, a ser solucionado e escondido da população. A solução para o lixo naquele momento não foi vista como algo complexo, pois bastava simplesmente afastá-lo, descartando-o em áreas mais distantes dos centros urbanos, denominados "lixões" (Fadini; Fadini, 2001).

Nos dias atuais, com a maioria das pessoas vivendo nas cidades e com o avanço mundial da indústria provocando mudanças nos hábitos de consumo da população, vem-se gerando um lixo diferente em quantidade e diversidade. Até mesmo nas zonas rurais encontram-se frascos e sacos plásticos acumulando-se devido a formas inadequadas de eliminação (IPT/Cempre, 1995). Para Bidone (1999), em um passado não muito distante a produção de resíduos era de algumas dezenas de quilos por habitante/ano; no entanto, hoje, países altamente industrializados como os Estados Unidos produzem mais de $700 \mathrm{~kg} / \mathrm{hab} / \mathrm{ano}$. No Brasil, o valor médio verificado nas cidades mais populosas é da ordem de $180 \mathrm{~kg} / \mathrm{hab} /$ ano (Fadini; Fadini, 2001, p. 9). 
Tratando-se do Brasil, a geração do lixo ainda é, em sua maioria, de procedência orgânica; entretanto, nos últimos anos vem se incorporando o modo de consumo de países ricos, o que tem levado a uma intensificação do uso de produtos descartáveis. A associação do crescimento populacional à intensa urbanização e às mudanças de consumo estão alterando o perfil do lixo brasileiro. As pessoas consomem mais, acarretando maior produção de lixo oriundo de suas compras, principalmente de alimentos e outros artigos adquiridos em supermercados.

No entendimento de Menezes et al (2005), o lixo representa uma grande ameaça à vida no planeta por duas razões essenciais: a sua quantidade e seus perigos tóxicos. Em toda parte do mundo a mídia incentiva as pessoas a adquirirem vários produtos e a substituírem os mais antigos por outros, mais modernos, provocando a insensatez do uso indiscriminado dos recursos naturais. Bauman (2001) declara que hoje vive-se em tempos fluidos, efêmeros e transitórios, em que carências pessoais são supridas pelo ato de comprar, por isso as pessoas compram cada vez mais produtos e os substituem em um período de tempo mínimo, gerando ainda mais resíduos e lixo nas cidades.

Este fato tem levado ao grande volume de lixo produzido no mundo, cujo aumento foi três vezes maior que o populacional nos últimos 30 anos. Fadini e Fadini (2001) destacam que a taxa de geração de resíduos sólidos urbanos está diretamente relacionada aos hábitos de consumo de cada cultura, existindo uma correlação estreita entre a produção de lixo e o poder econômico de uma dada população.

Os autores avaliam que do material descartado no Brasil, $76 \%$ é abandonado a céu aberto em locais impróprios, denominados popularmente de "lixões", o que permite a proliferação de vetores capazes de transmitir várias doenças. Para Lima e Silva, Guerra e Mousinho (1999), o "lixão" é uma forma inadequada de disposição final de resíduos sólidos, sem nenhum 
critério técnico, caracterizado pela descarga do lixo diretamente sobre o solo, sem qualquer tratamento prévio, colocando em risco o meio ambiente e a saúde pública.

Tommasi (1976) observa que os resíduos sólidos apresentam cada vez mais papéis, plásticos e vidros em inúmeros tipos de embalagens. Todo este material gera crescentes problemas de coleta, despejo e tratamento. Seus depósitos constituem-se, muitas vezes, em foco de crescimento de mosquitos e roedores causadores de doenças na população, contribuindo para a deterioração do ambiente humano. Além disso, o descarte inadequado de resíduos sólidos nos centro urbanos, sem qualquer tratamento, está contaminando os lençóis freáticos de várias regiões brasileiras. Essa situação é ainda pior ao se considerar que a água potável vai se tornar, em breve, um fator de grande competitividade entre as nações, pois está transformando-se em recurso cada vez mais escasso (Sanches et al., 2006).

Os resíduos gerados por aglomerações urbanas e por processos produtivos constituem um grande problema, tanto pela quantidade quanto pela toxicidade de tais rejeitos. Cabe ressaltar que a solução para tal questão não depende apenas de atitudes governamentais ou decisões de empresas, mas também deve resultar do empenho de cada cidadão, que tem o poder de recusar produtos que causem danos ambientais, participar de Organizações Não Governamentais ou simplesmente separar resíduos dentro de casa, facilitando com isso os processos de reciclagem. O conhecimento e a reflexão acerca do lixo é a única maneira de se iniciar um ciclo de decisões e atitudes que possam resultar em uma efetiva melhoria de qualidade ambiental e de vida (Fadini; Fadini, 2001).

O desafio está relacionado à discussão de como não gerar lixo ou, ao menos, minimizar a sua geração. Evidentemente que a melhor opção seria não gerar lixo, mas essa é uma alternativa nem sempre possível, uma vez que o modelo de vida adotado globalmente é pautado na produção e no consumo, que têm como consequência natural a geração de resíduos. Com o auxílio de programas de educação ambiental, entretanto, que constituem 
um processo informativo e formativo dos indivíduos, que desenvolvem habilidades e modificam atitudes em relação ao meio, tornando a comunidade educativa consciente de sua realidade global (Dias, 1992), pode-se desenvolver a consciência nos consumidores na escolha de determinados tipos de embalagens de produtos, rejeitando-se, por exemplo, aqueles produtos que possuem invólucros múltiplos e, às vezes, desnecessários e dando preferência a embalagens retornáveis em detrimento às descartáveis, bem como minimizando os desperdícios dentro de casa.

A recusa de tais produtos com múltiplas embalagens leva a indústria a ter uma atitude ambientalmente responsável por pressão do mercado consumidor e diminui em até $50 \%$ a quantidade de resíduos sólidos domésticos encaminhados aos aterros (Fadini; Fadini, 2001). Outra importante alternativa é o reuso dos resíduos e a reciclagem (ver Figura 2), que é facilmente explicada pela já difundida teoria de que resíduo nada mais é do que um material não adequadamente localizado no espaço e no tempo. Os autores explicitam:

A reciclagem pode ser considerada como o resultado de uma série de atividades através das quais materiais que se tornariam lixo ou estão no lixo são desviados, sendo coletados, separados e processados para uso como matéria-prima na manufatura de bens, feitos anteriormente apenas com matéria-prima virgem (Fadini; Fadini, 2001, p. 17).

A sua realização apresenta benefícios, conforme os autores, tais como: a diminuição da quantidade de lixo a ser aterrado, consequentemente aumentando a vida útil dos aterros sanitários; preservação dos recursos naturais; economia de energia; redução da poluição do ar e das águas e geração de empregos, com a criação de indústrias recicladoras. A reciclagem, contudo, não pode ser vislumbrada como a principal solução para a problemática do lixo, e sim como um elemento dentro de um conjunto de soluções. 
Fadini e Fadini (2001) argumentam que a separação de materiais do lixo aumenta a oferta de materiais recicláveis, porém se não houver demanda de produtos reciclados por parte da sociedade o processo é interrompido, os materiais abarrotam os depósitos e, por fim, são aterrados. Somente quando estiverem esgotadas as alternativas de redução de consumo, reuso e reciclagem é que se deve fazer a opção pelo tratamento, levando-se em consideração o ônus ambiental de cada alternativa que possa vir a ser adotada.

"A aparente utopia de um meio ambiente que concilie desenvolvimento associado à sustentabilidade ambiental, qualidade de vida e igualdade social só será alcançada com muita reflexão, boa vontade e esforços pessoal e comunitário" (Fadini; Fadini, 2001, p. 18). A responsabilidade, então, para a problemática do lixo, cabe não apenas ao governo e às empresas, mas à sociedade em sua totalidade.

\section{Procedimentos Metodológicos}

A presente investigação se configurou como qualiquantitativa. $\mathrm{O}$ estudo apresenta uma base qualitativa, por considerar a realidade subjetiva das pessoas, no caso específico, consumidores de supermercados e seus gestores. Como recurso utilizou-se a abordagem quantitativa, uma vez que as opiniões e informações dos consumidores foram traduzidas em dados estatísticos.

Trata-se de um estudo exploratório e descritivo com utilização de três grupos para investigação: consumidores de supermercados; gestores dos três principais supermercados localizados no perímetro central do município de Ijuí/RS e grupo de acompanhamento da geração de lixo doméstico.

O método survey selecionado para este estudo incluiu questionário e entrevistas. O questionário foi aplicado a uma amostra de 150 consumidores, adotando-se a técnica de amostragem não probabilística, constituindo-se em amostra de conveniência definida pela anuência dos consumidores abordados 
fora dos supermercados. A coleta dos dados ocorreu nos seguintes dias da semana: segunda-feira, quarta-feira e sábado, em horários alternados do dia. Os questionários coletados serviram de base para a elaboração do roteiro de entrevista pessoal realizada com os gestores dos três supermercados.

A pesquisa participante caracterizou-se pelo acompanhamento, feito por uma das investigadoras, da produção de lixo oriundo de compras supermercadistas, por meio da pesagem e da identificação de sua composição por uma amostra de conveniência, composta por 10 famílias, a quem se solicitou o acondicionamento de todo o lixo oriundo de compras realizadas em supermercados, no período de uma semana. Realizou-se a coleta e a pesagem do lixo, fazendo-se os devidos registros.

\section{Apresentação e Análise dos Resultados}

$\mathrm{Na}$ atualidade o descarte dos produtos e o destino dos resíduos tornam-se uma adversidade, especialmente nas grandes cidades. Isso porque o Brasil produz uma enorme quantidade de lixo, são 182.728 toneladas diárias, sabendo-se que cada pessoa produz quase um quilo de resíduo por dia (Cid, 2010). Trata-se de uma quantidade significativa, que preocupa devido aos danos ambientais resultantes do seu descarte, que na maioria dos casos é inadequado. Esse lixo se acumula, sendo jogado em locais com pouca estrutura, ou em lixões a céu aberto.

No município em que estão situados os supermercados investigados são recolhidos 1,2 mil tonelada de lixo por mês, destas apenas 60 toneladas de material reaproveitável para a indústria (Loureiro, 2010). Como o lixo de certo modo é considerado dinheiro, o autor estima que a cidade poderia obter uma receita de $\mathrm{R} \$ 2,5$ milhões ao ano caso a coleta seletiva fosse estabelecida por $100 \%$ dos moradores. Destaca-se que na composição deste grande volume de lixo estão resíduos e embalagens resultantes de compras realizadas em supermercados. 
Comprovou-se na pesquisa aplicada neste trabalho a quantidade significativa de lixo que as famílias produzem durante a semana, oriunda de produtos comprados em lojas supermercadistas e por elas consumidos. É importante salientar que a composição familiar explícita no Quadro 1, em termos de número de pessoas que compõem cada família, ainda interfere no volume de lixo gerado.

O estudo mostra que famílias compostas por crianças tendem a consumir maior número de alimentos, em especial aqueles embalados com materiais plásticos e papelão, além de frutas, cujas cascas e resíduos têm um peso maior. Outro fator a ser considerado é que em muitas famílias as refeições não são feitas nas residências, o que acarreta uma menor produção de lixo. E isso não quer dizer que não se produza, o que ocorre é que o lixo é processado e descartado em outros locais (onde são feitas as refeições).

Quadro 1- Quantidade de Lixo Produzida por Pessoa Diariamente

\begin{tabular}{|c|c|c|c|}
\hline $\begin{array}{c}\text { Identificação do } \\
\text { Consumidor }\end{array}$ & Composição familiar & $\begin{array}{c}\text { Lixo (Kg) } \\
\text { produzido } \\
\text { na semana }\end{array}$ & $\begin{array}{c}\text { Descarte de lixo em } \\
\text { (em quilos) por pessoa } \\
\text { por dia }\end{array}$ \\
\hline A & 2 adultos & $6,2 \mathrm{Kg}$ & 0,44 \\
\hline B & 3 adultos & $15,5 \mathrm{Kg}$ & 0,74 \\
\hline C & 2 adultos & $11,8 \mathrm{Kg}$ & 0,84 \\
\hline D & 2 adultos 2 crianças & $22,2 \mathrm{Kg}$ & 0,79 \\
\hline E & 4 adultos & $6 \mathrm{Kg}$ & 0,21 \\
\hline F & 2 adultos & $6,4 \mathrm{Kg}$ & 0,46 \\
\hline G & 2 adultos 1 criança & $17,65 \mathrm{Kg}$ & 0,84 \\
\hline H & 2 adultos & $7,54 \mathrm{Kg}$ & 0,54 \\
\hline I & 2 adultos 2 crianças & $18,33 \mathrm{Kg}$ & 0,65 \\
\hline J & 2 adultos 1 criança & $15,38 \mathrm{Kg}$ & 0,73 \\
\hline & MÉDIA & $12,7 \mathrm{~kg}$ & 0,62 \\
\hline
\end{tabular}

Fonte: Pesquisa de campo.

No estudo registrou-se uma média de 12,7 quilogramas semanais, compostos de vários itens que estão à venda nas lojas supermercadistas, entre eles: 
- Lixo orgânico: resíduos de comidas, cascas de frutas, verduras, legumes e restos de erva-mate;

- Lixo seco: embalagens plásticas, de papel, isopor e latas. As embalagens plásticas incluem garrafas pets, embalagens de miojo, geleia, catchup, maionese, detergente, iogurte; as embalagens de papel são compostas por caixas de sabão em pó, papel higiênico, guardanapos e toalhas de papel, tetra pak de leite e sucos, embalagens plásticas que acondicionam tortas, chocolates, cucas e bolos; isopor como embalagens para acondicionar legumes, carnes e produtos de padaria e ainda latas de cerveja, refrigerante e conservas.

O resultado consolida o exposto por Parente et al (2009), que enunciam uma sequência de atividades que se iniciam com a origem dos recursos e vão até o descarte do produto pelo consumidor final. A pesquisa, porém, mostra que neste descarte o destino da grande quantidade de lixo produzido ainda continua sendo o lixo comum e não a reciclagem, o que acaba por prejudicar gravemente o ambiente, conforme se pode observar na Figura 3.

Além disso, identificou-se que a média de lixo gerado por pessoa durante a semana é de $0,62 \mathrm{Kg}$, valor aproximado ao do Estado do Rio Grande do Sul em que Cid (2010) aponta para uma geração de 0,77 kg de lixo semanal. Essa grande quantidade de lixo produzida pode ser relacionada à reflexão de Daly (2005), quando o autor constata que hoje, objetos criados pelo homem atulham o meio ambiente, criando um planeta lotado. Para a maioria das pessoas a responsabilidade pelo lixo produzido parece se acabar no instante em que o caminhão da limpeza urbana recolhe os resíduos das fontes geradoras. O lixo, segundo Palhares (2003), deveria ser destinado à reciclagem formando, então, um processo cíclico que ainda é um desafio a ser encampado pela sociedade como um todo.

Os dados da pesquisa indicam que há distanciamento dessa proposta. A Figura 3, adaptada e ampliada a partir de Parente et al (2009) e Daly (2005) evidencia o caminho ora percorrido e as indesejáveis consequências. A alternativa ecologicamente correta é o contraponto da Figura 2. 
Figura 3 - Conexões da Cadeia de Valor do Varejo

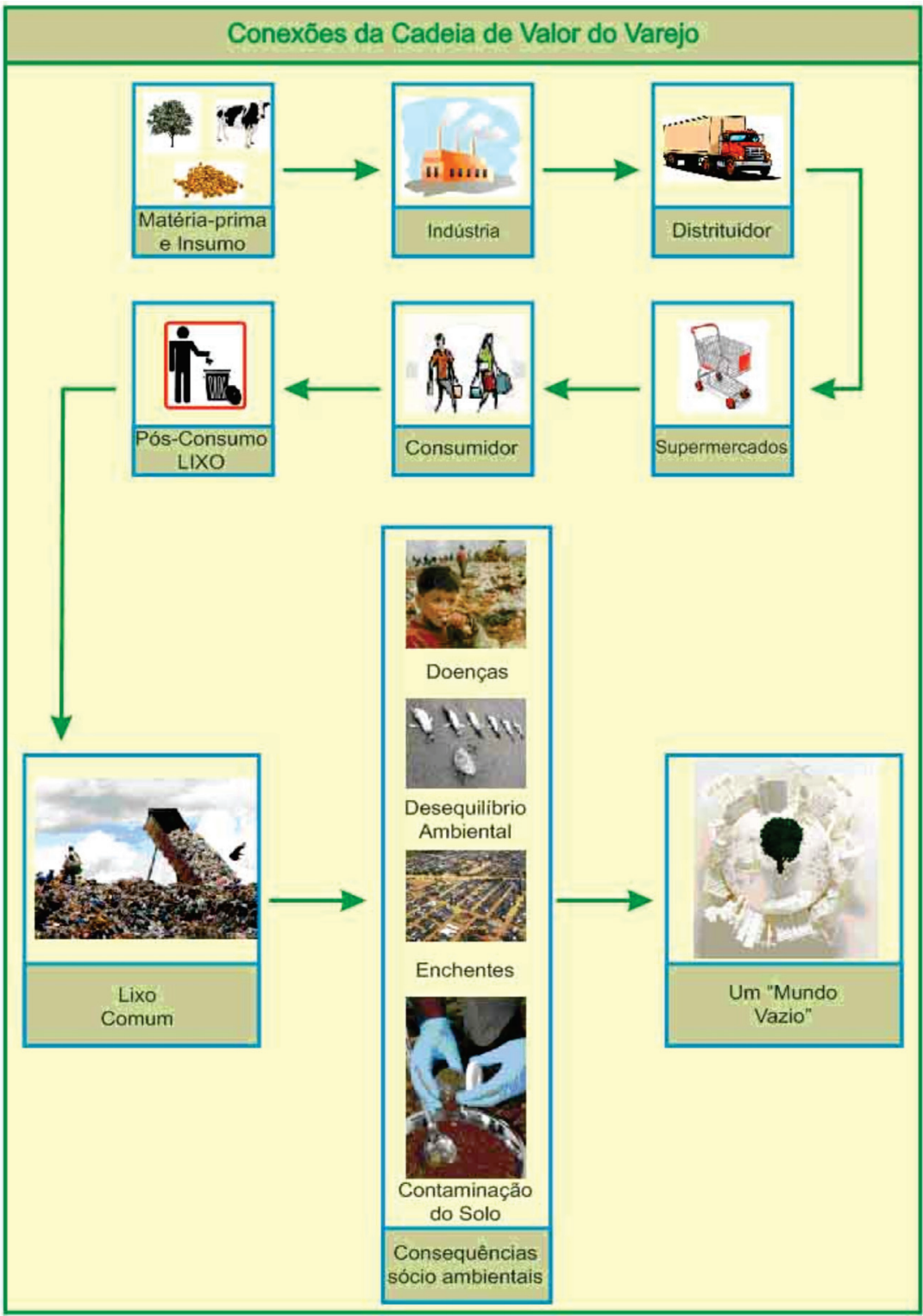

Fonte: Adaptada e ampliada a partir de Parente et al (2009) e Daly (2005). 
Os supermercados tendem a alocar a responsabilidade do descarte e da geração do lixo para o consumidor, fato identificado no presente estudo, e suas ainda incipientes ações apontadas como socialmente responsáveis não encontram eco na escolha dos consumidores por um determinado supermercado. A pesquisa revela também que, ao decidir em qual supermercado irão comprar as variáveis mais importantes na percepção dos consumidores são: menor preço disponível, considerado um fator determinante na escolha; rapidez no atendimento; variedade e qualidade de produtos e marcas; ambiente de loja agradável; estacionamento disponível; melhores prazos e formas de pagamento; proximidade de casa/trabalho; preocupação socioambiental; disponibilização de pontos de descarte de produtos; incentivo ao uso de sacolas retornáveis; serviços oferecidos; produtos de marca própria; espaços alternativos. Percebe-se que as variáveis referentes aos valores ambientais: a) incentivo e preservação ambiental e ações sociais; b) possuir ponto de descarte e c) disponibilizar sacola retornável, possuem médias respectivas de 3,59, 3,56 e 3,43, bem inferiores à média apresentada por outros fatores. O grau de importância - média aritmética ponderada, extraída da soma das pontuações atribuídas pelos respondentes e a quantidade de respostas obtidas - é demonstrado no Quadro 2.

Quadro 02 - Critérios de Avaliação para a Escolha de Supermercados

\begin{tabular}{|l|c|}
\hline Critérios de Avaliação para Escolha de Supermercados & Importância \\
\hline Menor Preço & 4,80 \\
\hline Rapidez no Atendimento & 4,50 \\
\hline Variedade e Qualidade dos Produtos e Marcas & 4,44 \\
\hline Ambiente de Loja Agradável & 4,31 \\
\hline Estacionamento Disponível & 4,00 \\
\hline Melhores Prazos e Condições de Pagamento & 3,92 \\
\hline Proximidade de Casa/Trabalho & 3,85 \\
\hline Incentivo a Preservação Ambiental e Ações Sociais & 3,59 \\
\hline Possuir Ponto de Descarte de Produtos & 3,56 \\
\hline Disponibilizar Sacola Retornável & 3,43 \\
\hline Serviços Oferecidos & 3,11 \\
\hline Produtos de Marca Própria & 3,03 \\
\hline Espaços Alternativos & 2,53 \\
\hline
\end{tabular}

Fonte: Pesquisa de campo. 
Constata-se que a preocupação e incentivo à preservação ambiental, com pontos de descarte de produtos, disponíveis nos supermercados, são ainda pouco valorizados pelos clientes no momento de decidir em que loja comprar. É uma questão cultural que levará anos ainda para ser incorporada aos costumes da sociedade e que hoje não se caracteriza como um motivo de compra determinante.

Apesar da pouca relevância que estes atributos supermercadistas possuem para o consumidor, torna-se impossível não perceber o quanto os supermercados estão envolvidos, na produção de lixo, provocando impactos ambientais. Questionados acerca da existência da preocupação socioambiental, os gestores afirmam possuir a consciência da importância de ações supermercadistas em benefício do ambiente e da sociedade, começando a realizar pequenas práticas voltadas à sustentabilidade, entretanto acabam minimizando a sua responsabilidade, destinando-a somente aos fornecedores e aos consumidores. Quanto ao uso da sacola retornável, por exemplo, os gestores consideram que a demanda foi maior na introdução da ideia, e que atualmente a utilização por parte dos clientes vem sofrendo queda. Este declínio no uso de sacolas retornáveis pode ser reflexo da falta de incentivo das próprias lojas. Inicialmente eram realizadas ações para lembrar e criar a consciência do uso, entretanto hoje a única ação é disponibilizar as sacolas no ponto de venda.

Quanto ao descarte dos produtos comprados em supermercados é comum resultar resíduos como materiais orgânicos e produtos tóxicos após o uso (pilhas, baterias, lâmpadas e embalagens diversas), o que gera preocupações em relação à preservação ambiental. Tratando-se desses resíduos de produtos, o destino para o descarte destas mercadorias é o lixo comum, não havendo nenhuma forma especializada de tratamento. Além dos produtos orgânicos e das embalagens jogadas no lixo diariamente, outros produtos preocupam pelo grau de periculosidade que seu descarte pode provocar, como as pilhas, baterias e lâmpadas. 
Quanto ao procedimento de descarte utilizado pelos consumidores no que se refere às pilhas e lâmpadas, $44 \%$ as descartam no lixo comum; $42 \%$ levam em postos de coletas específicos para estes materiais; $8,7 \%$ entregam em escolas; $2,7 \%$ dizem não saber que destino dar a tais produtos; 1,3\% entregam na Câmara de Vereadores do município e 1,3\% entregam em um supermercado que possui ponto de coleta (Gráfico 1). Ressalta-se neste quesito a responsabilidade dos gestores, uma vez que todos destacam a importância da existência de pontos de coletas para pilhas, baterias e lâmpadas, entretanto não tomam a atitude de agilizar sua execução, cuja ideia fica restrita ao discurso gerencial.

\section{Gráfico 1 - Destino dos Produtos Descartados}

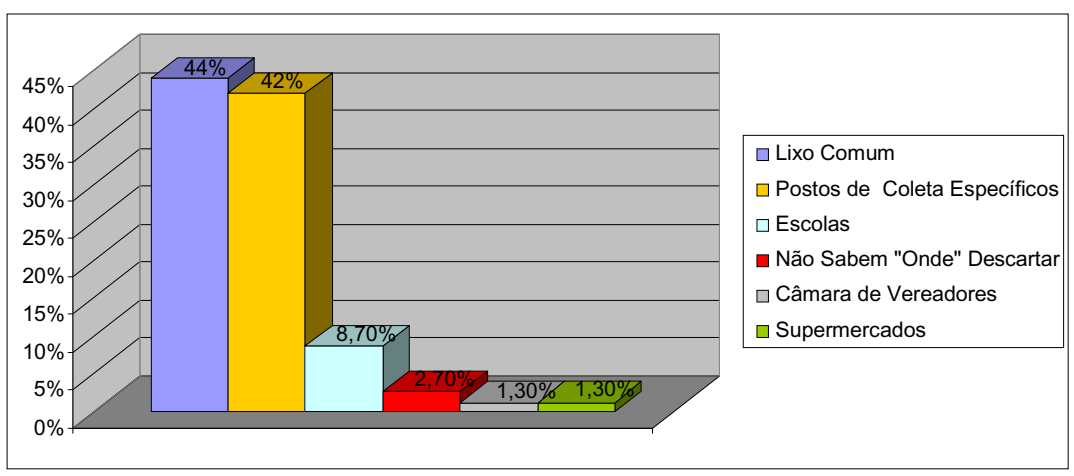

Fonte: Pesquisa de campo.

Estes resultados indicam que uma quantidade significativa de pessoas ainda descarta tais produtos no lixo comum, dado preocupante em termos ambientais. Loureiro (2010) destaca que no município investigado (Ijuí) a empresa responsável pela coleta seletiva de lixo recolhe em média 50 toneladas por dia, número este considerado baixo, pois grande parte da população ainda destina os materiais recicláveis para aterros sanitários e lixões.

Bardini (2010) alerta ainda que as pilhas, caracterizadas como lixo químico doméstico altamente perigoso, são compradas para uso em diversos produtos como rádios, brinquedos, controles remotos, jogos, lanternas e má- 
quinas fotográficas, no entanto quando o consumidor simplesmente as joga no lixo, muitas vezes não possui consciência e informações do quanto elas são prejudiciais. No Brasil são produzidas anualmente, segundo a Associação Brasileira da Indústria Elétrica e Eletrônica (Abinee), cerca de 800 milhões de pilhas, entre as chamadas secas (zinco-carbono) e alcalinas. Constituem-se num veneno lançado no meio ambiente diariamente por milhões de pessoas, cujo tempo de degradação varia de 100 a 500 anos, enquanto para os metais pesados este tempo é infinito.

Conforme dados da Associação Brasileira da Indústria Elétrica e Eletrônica (2012), uma pilha comum contém, geralmente, três metais pesados: zinco, chumbo e manganês, além de substâncias perigosas como o cádmio, o cloreto de amônia e o negro de acetileno. A pilha de tipo alcalina contém também o mercúrio, uma das substâncias mais tóxicas de que se tem conhecimento. $\mathrm{O}$ perigo ocorre quando se joga uma pilha ou bateria no lixo comum, pois há o risco de essas substâncias e metais pesados entrarem na cadeia alimentar humana, causando sérios danos à saúde. E esse é o procedimento ainda vigente, como apontam os resultados da pesquisa: pessoas descartando estes produtos no lixo comum e causando danos irreversíveis ao ambiente e à própria saúde da humanidade.

No caso dos produtos supermercadistas, Solomon (2002) comenta que é feito o descarte de lixo permanente, pois após cumprirem suas funções, tais produtos são, então, descartados. O consumidor julga que estes produtos não possuem mais utilidade e acabam descartando no lixo. Geram-se, então, toneladas de lixo no país produzidas diariamente, cuja composição tem grande participação de resíduos de compras de supermercados.

É importante mencionar ainda a questão do lixo gerado nas próprias operações supermercadistas, como os resíduos, as embalagens e papelões. De acordo com os gestores, existe uma preocupação quanto ao descarte de tais produtos e algumas ações vêm sendo postas em prática, tais como: venda de plásticos e papelões para empresas de reciclagem; compra de fornecedores de mercadorias que possuem embalagens confeccionadas 
com material reciclado; existência de tonéis nos quais são acondicionadas as gorduras resultantes de processos de fabricação de produtos da padaria e da confeitaria, recolhidos para descarte adequado.

O varejo supermercadista tem responsabilidade determinante na busca de alternativas relacionadas essencialmente ao descarte. Alternativas como o uso de sacolas retornáveis e biodegradáveis, a criação de locais para coleta de pilhas e lâmpadas usadas, compras de fornecedores considerados socialmente responsáveis, ações de educação e conscientização ambiental do consumidor e diminuição do impacto da embalagem na decisão de oferta por parte do varejo e de demanda por parte do consumidor, são algumas práticas que começam a vigorar e que auxiliam na redução dos danos ao meio ambiente.

Além disso, cabe destacar a relevância dos supermercados no âmbito social e sua crescente parcela de poder de barganha perante as indústrias. Enquanto detentor do poder, como ocupante de uma posição central e mais crítica no canal de distribuição, os supermercados podem exigir da indústria produtos sustentáveis, com redução do uso de embalagens plásticas, produção de embalagens mais simples e em menor quantidade. Em consequência, o consumidor irá comprar e produzir menos lixo doméstico. Identificou-se que os supermercadistas estão atuando na cadeia, apenas direcionados "para a frente" visando aos consumidores, porém devem envolver também os seus fornecedores e as indústrias, que são as grandes fontes geradoras de embalagens e lixo.

\section{Considerações finais}

O varejo supermercadista possui grande relevância no cenário brasileiro. O que preocupa, entretanto, são os impactos que o resultado de suas operações, no que se refere ao descarte dos produtos, acabam provocando, especialmente quanto à quantidade de lixo gerada pelas compras realizadas em suas lojas. Neste quesito está o maior gargalo da atuação dos supermercados. 
A preocupação maior é com o descarte dos produtos e o destino dos resíduos, o que se torna um problema, em especial nas grandes cidades. $\mathrm{O}$ estudo mostra que as famílias produzem 12,7 quilos de lixo na semana oriundos de compras supermercadistas, os quais acabam sendo descartados em lixo comum, resultando em problemas ambientais e de saúde da população.

Os gestores dos supermercados investigados afirmam possuir a consciência da importância de ações supermercadistas em benefício do ambiente, entretanto acabam se esquivando da sua responsabilidade enquanto intermediários do canal de distribuição. Transferem essa responsabilidade ao fabricante e ao consumidor, e nenhuma atitude ou ação maior é por eles desenvolvida. Enquanto detentor do poder, como ocupante de uma posição central e mais crítica no canal de distribuição (Figura 2), os supermercados podem exigir e ser parceiros da indústria na priorização de produtos sustentáveis, com redução do uso de embalagens plásticas, produção de embalagens mais simples e em menor quantidade.

Constata-se que o varejo supermercadista tem uma responsabilidade importante na busca de alternativas relacionadas essencialmente ao descarte. Alternativas como o uso de sacolas retornáveis e biodegradáveis, a criação de locais para coleta de pilhas e lâmpadas usadas, compras de fornecedores considerados socialmente responsáveis, ações de educação e conscientização ambiental do consumidor e diminuição do impacto da embalagem na decisão de oferta por parte do varejo e de demanda por parte do consumidor, são algumas práticas que começam a vigorar e que auxiliam na redução dos danos ambientais.

Cabe aos gestores, então, colocar em prática tais ações em suas lojas, para que elas não acabem sendo apenas parte de um discurso gerencial vazio e sem ganhos para a sociedade. Se cada elemento da cadeia produtiva - indústria, varejo e consumidor - assumir para si suas responsabilidades, a quantidade de lixo gerado será menor e, em consequência, os impactos socioambientais também serão minimizados, além do impacto positivo na imagem que o consumidor terá do setor em relação à questão ambiental. 


\section{Referências}

ASSOCIAÇÃO BRASILEIRA DA INDÚSTRIA ELÉTRICA E ELETRÔNICA. ABINEE. Disponível em: <http://www.abinee.org.br/noticias/rel2009.htm>. Acesso em: 19 set. 2012.

ALIGLERI, Lilian; ALIGLERI, Luiz Antonio; KRUGLIANSKAS, Isak. Gestão ambiental: responsabilidade e sustentabilidade do negócio. São Paulo: Atlas, 2009.

BARDINI, Rogério. Pilhas e baterias: o lixo dentro de casa. Reciclar é preciso. Disponível em: <http://www.reciclarepreciso.hpg.ig.com.br/pilhasbaterias.htm>. Acesso em: 19 set. 2010.

BAUMAN, Zygmunt. Modernidade líquida. Rio de Janeiro: Jorge Zahar Editor, 2001.

CID, Thiago. Alta tecnologia a serviço do lixo. Época, n. 364, p. 22-23, 12 jul. 2010.

DALY, H. E. Sustentabilidade em um mundo lotado. Scientific American Brasil., 4 (41), São Paulo, out. 2005.

DIAS, G. F. Educação ambiental: princípios e práticas. 1. ed. São Paulo: Gaya, 1992.

ENGEL, James F; BLACKWELL, Roger D.; MINIARD, Paul W. Comportamento do consumidor. Rio de Janeiro: LTC, 2000.

FADINI, Pedro Sérgio; FADINI, Almerinda Barbosa. Lixo: desafios e compromissos. Cadernos temáticos de Química Nova na Escola. São Paulo: Sociedade Brasileira de Química, v. 1. p. 9-18, maio 2001.

KOTLER, Philip; ARMSTRONG, Gary. Principios de marketing. Rio de Janeiro: LTC, 1999.

LIMA E SILVA, Pedro Paulo de; GUERRA, Antonio J. T.; MOUSINHO, Patrícia. Dicionário brasileiro de ciências ambientais. Rio de Janeiro: Thex, 1999.

LOUREIRO, Janis. Raio X do lixo. Jornal da manhã, Ijuí, 30 e 31 de out. de 2010. Caderno especial Desenvolvimento Urbano, p. 4.

MENEZES, Marilia Gabriela de et al. Lixo, cidadania e ensino: entrelaçando caminhos. Química Nova na Escola, São Paulo: Sociedade Brasileira de Química, v. 22, p. 38-41, nov. 2005. 
MIOTO, Ricardo. Banir material plástico não é consenso entre ambientalistas. Folha de São Paulo. Disponível em: <http://www.gvces.com.br/index. php?page $=$ Noticia\&id=209091>. Acesso em: 7 ago. 12 .

OTTMAN, Jacquelyn A. Marketing verde. São Paulo: Makron Books, 1994.

PALHARES, Marcos Fruet. O impacto do marketing "verde" nas decisões sobre embalagens das cervejarias que operam no Brasil. 2003. Dissertação (Mestrado em Administração) - Departamento de Administração, Faculdade de Economia, Administração e Contabilidade, Universidade de São Paulo, 2003.

PARENTE, Juracy; GELMAN, Jacques; CARDOSO, Roberta (coord.). Fórum de Varejo e Consumo Sustentável: experiências, debates e desafios. São Paulo: FGV, 2009.

SANCHES, Sérgio M.; SILVA, Carlos Henrique Tomich de Paula da; VESPA, Izabel C.G.; VIEIRA, Eny Maria. A Importância da compostagem para a educação ambiental nas escolas. Química Nova na Escola, São Paulo: Sociedade Brasileira de Química, v. 23, p. 10-13, maio 2006.

SOLOMON, Michael R. O comportamento do consumidor: comprando, possuindo e sendo. 5. ed. Porto Alegre: Bookman, 2002.

TOMMASI, Luiz Roberto. A degradação do meio ambiente. São Paulo: Nobel, 1976.

Recebido em: 10/4/2013

Aceito em: 6/6/2013 